\title{
Failure of SCS MR-Conditional Modes Due to High Impedance: A Review of Literature and Case Series
}

\author{
Rohan Jotwani · Alaa Abd-Elsayed · Kristine Villegas · Ahmed Shakil • \\ Amitabh Gulati · Dawood Sayed · Christopher Lam • Neel Mehta
}

Received: September 18, 2020 / Accepted: November 13, 2020 / Published online: November 21, 2020

(C) The Author(s) 2020

\begin{abstract}
Introduction: Magnetic resonance imaging (MRI) conditional modes are a novel feature for certain Food and Drug Administration (FDA)approved spinal cord stimulation (SCS) devices. However, there is a paucity of literature around the limitation of MRI-conditional modes ("MRI safe"), specifically in clinical scenarios where urgent MRIs may be needed. One such limitation is load impedance, referring to the circuit's resistance to the current being generated by the system. High impedance can limit the MRIconditional mode capability, presenting
\end{abstract}

R. Jotwani · K. Villegas · A. Shakil · N. Mehta Anesthesiology, NewYork-Presbyterian/Weill Cornell Medical Center, New York, NY, USA

A. Abd-Elsayed ( $\square)$

Anesthesiology, University of Wisconsin School of

Medicine and Public Health, Madison, WI, USA

e-mail: alaaawny@hotmail.com

A. Gulati

Anesthesia and Critical Care, Memorial Sloan

Kettering Cancer Center, New York, NY, USA

D. Sayed · C. Lam

Anesthesiology, University of Kansas Medical

Center, Kansas City, KS, USA potential harm to a patient undergoing an MRI or make an MRI unable to be completed.

Methods: Three cases were identified, and informed consent was obtained. All information was obtained via retrospective chart review. Results: In this case series of three patients where MRI-conditional SCS systems were unable to be placed in "MRI safe" settings, preventing timely MRI study completion in the setting of high impedance, all three were required to undergo alternative imaging including CT scans, and two patients ultimately had the system explanted and one chose to be re-implanted after completion of scans.

Conclusion: This case series highlights the need for further investigation of impedance in SCS systems and potential limitations for future MRI usage. The review of literature of impedance in SCS shows both device- and physiologic-related etiologies for changes in impedance that warrant consideration by the implanting physician.

Keywords: Conditional; Impedance; MRI; SCS 


\section{Key Summary Points}

Spinal cord stimulator impedances fall within a wide range.

At certain impedances MRI may not be safe.

It is important to weigh the risks and benefits when ordering MRI in patients with a spinal cord stimulator.

\section{DIGITAL FEATURES}

This article is published with digital features, including a summary slide, to facilitate understanding of the article. To view digital features for this article go to https://doi.org/10.6084/ m9.figshare.13227845.

\section{INTRODUCTION}

Magnetic resonance imaging (MRI) is a commonly used radiological modality in the diagnosis and surveillance of disease. Approximately $82 \%$ of patients with spinal cord stimulators (SCS) will need an MRI scan within 5 years after implant [1]. Furthermore, we have previously shown that certain populations present special consideration for MRI screening, such as the high-risk breast cancer population, and MRI surveillance and staging, such as aging men ( $>50$ years old) at risk for prostate cancer or individuals diagnosed with rectal cancers [2]. MRI represents a significant potential risk to patients with an implanted spinal cord stimulator, as rotational and spatial gradient forces between the MRI machine and the stimulator can damage tissues and the device itself [3]. To ameliorate issues between SCS and MRI, a number of SCS manufacturers have developed an MRI-conditional mode. Table 1 contains a summary of publicly available information regarding MRI conditionality across different device manufacturers. Professional societies
Table 1 MR conditionality across various SCS device manufacturers

\begin{tabular}{ll}
\hline Company & MR conditions \\
\hline Nevro & $\begin{array}{c}\text { Eligible for full body }(1.5 \mathrm{~T} \text { only) and head } \\
\text { and extremity } 1.5 \mathrm{~T} \text { and } 3.0 \mathrm{~T} .3 .0 \mathrm{~T} \\
\text { requires horizontal cylindrical closed bore } \\
\end{array}$ \\
& MRI systems \\
Medtronic & $\begin{array}{l}\text { No readily available information regarding } \\
\text { MRI guidelines }\end{array}$ \\
Abbott & $\begin{array}{c}\text { Eligible for } 1.5 \mathrm{~T} \text { cylindrical-bore magnet, } \\
\text { horizontal field MRI system only }\end{array}$ \\
Boston & Eligible for $1.5 \mathrm{~T}$ horizontal closed bore \\
Scientific & MRI system only \\
StimWave & No readily available information regarding \\
& MRI guidelines
\end{tabular}

have also published comprehensive guidelines to help guide clinical practice [4]. MRI-conditional mode is made possible by changes in the design of both the leads and the implantable pulse generator (IPG) that decreases or differently dissipates the energy absorbed by tissues to meet FDA specific absorption rate (SAR) requirements [5]. Despite these advancements, MRIs may still not be fully possible. Here we describe a case series of SCS devices that were unable to safely transition to MRI-conditional mode because of high impedance.

\section{CASE SERIES}

All data reviewed in this case series was retrospective and collected through the electronic health record.

Ethics committee approval was not required for this particular study given no identifiable material and as a part of a quality assurance project. The study was performed in accordance with the Helsinki Declaration of 1964, and its later amendments. All subjects provided informed consent to participate in the study and for publication of any identifying information included in the manuscript. 


\section{Case 1}

The patient is a 70-year-old woman with chronic lumbar radiculopathy status-post failed laminectomy for spinal stenosis at L4-L5 and SCS implant with dual parallel contact leads implanted at the T7/8 disc space. Nine months following implant, the patient presented to the hospital for a transcatheter aortic valve replacement (TAVR) due to severe aortic stenosis.

The patient underwent an uneventful TAVR with the SCS placed in "surgery mode" prior to surgery. On postoperative day 2 , a stroke code was activated due to right upper and lower extremity weakness, with a National Institutes of Health (NIH) Stroke Scale score of 10. Emergent CT head showed a likely new stroke in the left centrum semiovale. An urgent MRI was requested, but the SCS was unable to transition to MRI-conditional mode due to high impedance in five unilateral contact leads despite multiple attempts from the manufacturer's representative and consulting pain physicians. Device interrogation and X-ray imaging did not show any obvious deficit in the device activity, electrode integrity, lead placement, battery life, or impulse generator integrity. During this time, the patient showed improved motor function of both right upper and lower extremities. A multidisciplinary team decided to delay an inpatient MRI brain, as the risk of immediate SCS explant surgery outweighed the benefits to management from immediate imaging.

The patient was discharged on postoperative day 5 with improvement, but still worse than baseline right lower extremity weakness and aphasia. At 2-week follow-up in the outpatient pain clinic, she reported resolution of her aphasia and some continued right side weakness, stating she was doing extensive physical and occupational therapy and taking steps with a walker during these sessions. At home she was continuing to use a motorized scooter, displaying a new functional deficit not present preoperatively. Of note, she continued to receive similar pain relief from the SCS system as preoperatively and thus decided against explantation given the improving nature of her neurological symptoms.

\section{Case 2}

The patient is a 67-year-old man with a history of radiculopathy status-post failed back surgery at levels L2-S1. He eventually had a spinal cord stimulator implanted in 2017 and then presented with a suspected new lumbar disc herniation in 2019. The patient had previous successful MRIs post-implant; however, the SCS was unable to transition to MRI-conditional mode due to high impedance for the more recent MRI need. There were no suspected hardware malfunctions and no interventions made at that time due to the non-emergent nature of the scan, and CT lumbar spine was utilized instead. One month later, the patient's SCS was again interrogated and found to be within normal impedance thresholds allowing completion of a lumbar MRI with no adverse outcomes. One year later, the patient needed a repeat MRI lumbar spine for a new radicular pain suspicious of a herniated disc, and again high impedances prevented a scheduled MRI. The system has since been explanted due to this limitation. The patient was ultimately re-implanted with a different manufacturer's stimulator.

\section{Case 3}

The patient is a 43-year-old man with lumbar radiculopathy following a motor vehicle collision who underwent SCS implant in 2017 with dual parallel contact leads placed at the T8/T9 disc space. Lead migration was discovered at $\mathrm{T} 9$ and T11 1 month post-implant, but no increased impedance was recorded at that time. Following SCS implantation, the patient developed metastatic melanoma (stage IIIB) in 2019 with the primary left shoulder site requiring multiple MRI scans for surveillance of disease. Impedance testing at the time of the MRI scan measured as elevated in four contact leads with values $>10,000 \Omega$, preventing placement into MRI "safe" mode. Ultimately the patient did not have the MRI. A summary of all MRI scans 
Table 2 Summary of MRI attempts for Case 3

\begin{tabular}{llll}
\hline $\begin{array}{l}\text { MRI } \\
\text { attempt }\end{array}$ & $\begin{array}{l}\text { MRI } \\
\text { imaging }\end{array}$ & $\begin{array}{l}\text { Pain physician/ } \\
\text { device } \\
\text { representative } \\
\text { aware? }\end{array}$ & $\begin{array}{l}\text { Scan } \\
\text { completed? }\end{array}$ \\
\hline 1 & $\begin{array}{c}\text { Thoracic } \\
\text { MR }\end{array}$ & $\begin{array}{l}\text { Yes, high } \\
\text { impedance } \\
\text { recorded in four } \\
\text { lead contacts }\end{array}$ & $\begin{array}{l}\text { Yes, no } \\
\text { negative } \\
\text { outcomes } \\
\text { reported }\end{array}$ \\
2 & Chest & No & Cancelled \\
3 & MR & Cancelled \\
4 & MR & No & Cancelled \\
& Mead & Yes, high \\
& & $\begin{array}{l}\text { impedance } \\
\text { recorded in four } \\
\text { lead contacts }\end{array}$ & \\
& & &
\end{tabular}

ordered and their outcomes are detailed in Table 2.

\section{DISCUSSION}

Our case series highlights the importance of recognizing and understanding the conditionality of MRI "safe" modes on SCS systems, specifically with regard to impedance. A review of the literature shows few, if any, guidelines that comprehensively explain all MRI-conditional variables and how to troubleshoot in a case of urgent or emergent MRI. Further, Table 3 compiles all the publicly available information mentioning impedance from online clinician guides of MRI-conditional stimulators across various companies. Closer analysis of this text reveals gaps in discussion of MRI conditionality and high impedance. Limited companies mention specific safe thresholds, however the values range between 4500 and $10,000 \Omega$, and likely depend on the device itself. Increasing access to impedance thresholds, safety studies, and contingency plans would help implanting physicians not only in stratifying which candidates would benefit from MRI-conditional systems, but also in monitoring and effectively planning for emergencies necessitating MRI (Table 4).

Much of the impedance literature focuses on its utility as a diagnostic tool for hardware failure. However, our experience suggests that likely a combination of internal and external etiologies may play a role in high impedance. Case 3 provides a scenario where the patient had known lead migration for 2 years prior to the development of focal high impedance, suggesting a pattern more consistent with epidural fibrosis than lead migration or IPG disconnect. Both Case 1 and Case 2 provide scenarios where there is no obvious etiology for high impedance. This also suggests there may yet be etiologies for high impedance requiring further investigation. Together, the three cases highlight a spectrum of outcomes and decisionmaking paradigms, from urgent MRI being delayed in the midst of CVA (Case 1) to repeat MRI being cancelled after no adverse outcomes reported during the initial scan with the same impedance noted (Case 3).

In the context of spinal cord stimulation, load impedance refers to a device's resistors creating an opposition to the voltage that travels as a current through the integrated circuit of a generator and the electrodes [6]. According to Ohm's law, the impedance of a system increases when a higher amount of voltage is required to produce a relatively small current $(R=V / I$, where $R$ is "resistance/impedance", $V$ is voltage, and $I$ is current). This is primarily true for voltage-controlled stimulation devices, as voltage distributions in the target neural and connective tissue depend upon the impedance of the electrode-tissue interface [7]. Alternatively, spinal cord stimulation with current-controlled devices has been shown to minimize fluctuations in impedance in deep brain stimulation [7]. Impedance is also directly proportional to the energy consumption of the IPG, thus making it also proportional to the battery life of the device itself [8]. However, more recently this theory has been challenged to suggest there is an inverse relationship between impedance and the energy: $E=(V 2 \times$ pulse width $\times f) / R$ [9]. SCS systems are unable to transition to MRI-conditional modes in states of high impedance, as interactions generated by the MRI machine can 
Table 3 Review of literature for SCS and high impedance

\begin{tabular}{|c|c|c|}
\hline Study & Factor & Findings \\
\hline $\begin{array}{l}\text { Roguin } \\
\text { et al. }\end{array}$ & $\begin{array}{l}\text { Lead } \\
\text { fracture }\end{array}$ & In pacemakers, lead fracture has led to instances of significant intrathoracic tissue damage [8] \\
\hline $\begin{array}{r}\text { Kumar } \\
\text { et al. }\end{array}$ & $\begin{array}{l}\text { Lead } \\
\text { fracture }\end{array}$ & $\begin{array}{l}\text { Lead fracture was one of the drivers behind long-term failure rates of } 5.9 \% \text {, some diagnosed by } \\
\text { routine impedance testing [9] }\end{array}$ \\
\hline North et al. & $\begin{array}{l}\text { Lead } \\
\text { migration }\end{array}$ & $\begin{array}{l}\text { Four out of } 291 \text { patients experienced lead migration leading to unsafe impedance levels and } \\
\text { requiring surgical revisions [12] }\end{array}$ \\
\hline Alo et al. & $\begin{array}{l}\text { Vertebral } \\
\text { level }\end{array}$ & $\begin{array}{l}\text { Impedance in the cervical region was tested to be } 351 \pm 90 \Omega \text {, compared to the lower-thoracic } \\
\text { region where impedance was } 547 \pm 151 \Omega[16]\end{array}$ \\
\hline $\begin{array}{l}\text { DeJongste } \\
\text { et al. }\end{array}$ & $\begin{array}{l}\text { Age of } \\
\text { implant }\end{array}$ & $\begin{array}{l}\text { After the first } 4 \text { weeks post-implant, the mean impedance was } 821 \Omega \text { increased from the } \\
\text { starting impedance } 748 \Omega[17]\end{array}$ \\
\hline $\begin{array}{l}\text { Ranson } \\
\text { et al. }\end{array}$ & $\begin{array}{l}\text { Epidural } \\
\text { fibrosis }\end{array}$ & $\begin{array}{l}\text { Case study where effects of stimulation on bladder function were eventually lost due to } \\
\text { epidural fibrosis. This led to explantation of the device [14] }\end{array}$ \\
\hline $\begin{array}{l}\text { Cameron } \\
\text { et al. }\end{array}$ & $\begin{array}{l}\text { Postural } \\
\text { changes }\end{array}$ & $\begin{array}{l}\text { In } 20 \text { patients, the threshold for inducing paresthesia was the lowest when lying down. } \\
\text { Paresthesia required } 0.113 \pm 0.062 \mu \mathrm{C} \text { for leads in the cervical region and } \\
0.494 \pm 0.297 \mu \mathrm{C} \text { for leads in the thoracic region [18] }\end{array}$ \\
\hline Olin et al. & $\begin{array}{l}\text { Postural } \\
\text { changes }\end{array}$ & $\begin{array}{l}\text { In a sample of } 42 \text { patients, } 95 \% \text { of patients experienced a voltage increase between } 11 \text { and } 25 \% \\
\text { when patients moved from supine to sitting or standing positions [19] }\end{array}$ \\
\hline Ross et al. & $\begin{array}{l}\text { Postural } \\
\text { changes }\end{array}$ & $\begin{array}{l}\text { Different distances between fixed electrodes and the spinal cord due to patient movement can } \\
\text { cause different perceptions of paresthesia [20] }\end{array}$ \\
\hline
\end{tabular}

lead to a number of potential harms, including potential damage or fracture of the leads, excessive heating of the electrodes causing an unsafe increase in SAR, unwanted stimulation due to voltage induction, and battery exhaustion of the device. Specifically, the relationship between tissue heating and high impedance states varies based on the type of stimulation, with current-controlled stimulation having been shown to increase heating of tissues, while voltage-controlled stimulation is associated with decreased heating [10].

Incidence of thermal heating of tissue already occurs with the use of SCS. Various frequencies have been associated with increases in temperature to adjacent tissue in a bio-heat model [8]. The $10 \mathrm{kHz}$ waveform may increase the temperature of surrounding tissue, and models suggest the increase to be 1.7 and $1.5^{\circ} \mathrm{C}$ to the cervical and thoracic spinal cord, respectively, which is in distinction to lower frequencies, which have significantly less increases in temperature to the surrounding tissue [11]. Patient characteristics such as epidural lipomatosis may also lead to high impedance and thereby increases in temperature [12]. Regardless of waveform, certain parameters in SCS settings, such as amplitude, pulse width, and frequency, can be modulated to increase charge density [13]. It is thought that increases in charge density, and perhaps a resulting increase in temperature, may exhibit effects on the spinal cord that result in improved pain control. While this data suggests safety when temperature and charge density increase, clearly there is a fine line before deleterious effects may occur.

Few studies have characterized the effects of impedance in the context of MRI compatibility. A study by De Andres et al. that followed 31 
Table 4 Impedance testing/threshold documentation based on clinician manuals

\begin{tabular}{lc}
\hline Company & Impedance testing/thresholds \\
\hline Nevro & $\begin{array}{r}\text { While performing an impedance check, do } \\
\text { not perform an MRI if any lead electrode } \\
\text { impedance is greater than or equal to } \\
10,000 \text { ohms }\end{array}$ \\
Medtronic & $\begin{array}{c}\text { No readily available information regarding } \\
\text { MRI guidelines and impedance }\end{array}$ \\
Abbott & No maximum impedance thresholds \\
& mentioned in clinician's manual \\
Boston & For intraoperative stimulation testing: \\
Scientific & "Impedances over 4500 ohms are \\
& considered to be resultant from open or \\
& unconnected wires" \\
StimWave & No readily available information regarding \\
& MRI guidelines and impedance
\end{tabular}

patient cases of SCS/MRI interactions described one case where impedance rose to greater than $4000 \Omega$ on several of the lead poles following MRI [7]. Additionally, two other cases reported total battery exhaustion following MRI due to higher energy consumption during the scan [14]. Other reports have shown similar changes to battery life during MRI with implantable devices [15]. Finally, there have been case reports of voltage induction during MRI correlating with high baseline impedance and resulting in unwanted stimulation $[16,17]$.

Both internal and external factors affect the impedance of the SCS circuit. A summary of all these factors can be found in Table 2. Internal factors, otherwise known as "hardware failures", revolve around the integrity of the device circuit starting from the IPG to the lead poles. Lead fracture is one of the more common complications of device-related high impedance, with an occurrence rate of $5.9-9.1 \%$ $[18,19]$. Per guidelines set by the International Neuromodulation Society (INS) in 2014 on the safety and risk reduction of complications in neurostimulation, impedance testing of electrodes is a means of diagnostic testing for suspected macro- or micro-fractures [20]. These fractures result in higher resistance in the circuit, with greater voltage required to achieve the same stimulation. Additionally, lead migration, estimated to occur in $13-22.6 \%$ of cases, may cause misalignment of the lead poles resulting in circuit changes that require greater voltage to achieve the same stimulation $[19,21,22]$. With regard to failure of the IPG, impedance may also be diagnostic for a failure of the communication leads with external telemetry. The management of high impedance in the setting of these system malfunctions likely requires replacement or disuse of the malfunctioning equipment, although in certain circumstances there may be options to program around micro-fractures of the leads [23].

Beyond hardware failures, there are a number of potential external etiologies for high impedance such as tissue impedance, vertebral level of electrodes, time since implantation, age of the patient, epidural fibromatosis, and previous spinal surgery. Results reported by Alo et al. show that SCS leads located in lowerthoracic regions tend to produce higher impedance within circuits than mid-cervical leads by approximately $200 \Omega$. This is due to increased CSF and space in lower-thoracic regions, thereby decreasing dural contact with electrodes and necessitating greater energy consumption [24]. DeJongste et al. showed that the mean impedance in their cohort rose over time for chronic implants in patients undergoing SCS for anginal pain, potentially due to fibrotic tissue that develops over leads [25]. Ranson et al. similarly have written case studies on changes in impedance due to epidural fibrosis, although specific risk factors are unclear at this time. Finally, a number of studies have looked at the relationship between postural changes and impedance, showing that the voltage requirement, and thus the impedance, increases when moving from supine to standing position, but this is unlikely to cause clinically significant, irreversible changes to impedance resulting in crossing the threshold to MRI incompatibility [26-28].

Different clinical circumstances might have necessitated immediate explantation of the SCS device for the patients in our case series, causing 
an additional surgical procedure, a major delay in care, and psychological, physical, and economic burden. In contrast, the Russo et al. retrospective review of approximately 1500 nonMRI-conditional pacemakers or implantable cardioverter defibrillators (ICDs) that underwent $1.5 \mathrm{~T}$ imaging suggests that the risk of lead/device failure or poor patient outcomes is extremely limited (six cases of selfterminating atrial fibrillation or flutter, no cases of device/lead failure), even in the few cases where the device underwent a scan with high impedance [14]. Nevertheless, with limited guidelines and an incomplete understanding of the etiology of high impedance, the ability to troubleshoot the SCS system efficiently was limited, leading to the binary choice between delaying/avoiding MRI and explantation. These issues may become more commonplace for practitioners moving forward, as patients who are at high risk for needing an MRI often warrant placement of these specific MRI-conditional systems, such as patients in need of cancer surveillance.

Computational modeling is a useful tool to help predict clinical responses to theoretical scenarios. Already used to predict the mechanism of action for novel $10 \mathrm{kHz}$ frequencies in deep brain stimulation (DBS) in generating moderate localized tissue heating, it may serve a role in creating new MR-safe electrodes and stimulation systems for dorsal column spinal cord stimulation as it has for DBS [9]. Electromagnetic (EM) modeling is a readily available technique utilized to predict how implanted medical devices interact with the MRI EM fields, and it is conceivable that this modality can be used to help develop novel device components that do not increase impedance over time to mitigate this issue [29].

Although many of the factors that can lead to high impedance within an SCS system may be unintended or unavoidable, there are best practice techniques and practical considerations that can make the possibility of encountering high impedance issues after implant less likely. Hardware failures may be mitigated by visual inspection of the stimulator leads prior to implant for obvious kinks or damaged electrodes. When placing spinal cord stimulator leads, proper spacing and avoidance of electrodes overlaying each other is a best practice to avoid impedance or electrode interference after implantation. Utilizing the best technique for anchoring of leads to avoid migration and misalignment of leads is also important to ensure long-term efficacy and avoid impedance issues within the SCS system. Finally, an impedance check of the SCS system prior to final implantation of the SCS system is vital to ensuring proper connection of leads to the IPG.

These cases highlight the need for further discussion, investigation, and counseling of patients regarding factors that may prevent MRI-conditional SCS systems from meeting criteria for MRI scan.

\section{ACKNOWLEDGEMENTS}

We thank the participants of the study.

Funding. No funding or sponsorship was received for this study or publication of this article.

Authorship. All named authors meet the International Committee of Medical Journal Editors (ICMJE) criteria for authorship for this article, take responsibility for the integrity of the work as a whole, and have given their approval for this version to be published.

Disclosures. Dawood Sayed serves as a consultant to Abbott, Boston Scientific, Flowonix, Medtronic, Nevro, PainTEQ, SPR Therapeutics, Vertos, and Vertiflex. Amitabh Gulati serves as a consultant to Medtronic, Flowonix, SPR Therapeutics, Nalu Medical, and Bausch Health; advisory board of AIS. Neel Mehta serves as a consultant to Nevro and has received research support from Medtronic, Nevro, Boston Scientific and Abbott. Alaa Abd-Elsayed serves as a consultant of Medtronic, Avanos and StimWave. Ahmed Shakil has performed contracted research for Boston Scientific. Christopher Lam, Kristine Villegas and Rohan Jotwani have nothing to disclose. 
Compliance with Ethics Guidelines. Ethics committee approval was not required for this particular study, as there was no identifiable material and it was part of a quality assurance project. The study was performed in accordance with the Helsinki Declaration of 1964 and its later amendments. All subjects provided informed consent to participate in the study and for publication of any identifying information included in the manuscript.

Open Access. This article is licensed under a Creative Commons Attribution-NonCommercial 4.0 International License, which permits any non-commercial use, sharing, adaptation, distribution and reproduction in any medium or format, as long as you give appropriate credit to the original author(s) and the source, provide a link to the Creative Commons licence, and indicate if changes were made. The images or other third party material in this article are included in the article's Creative Commons licence, unless indicated otherwise in a credit line to the material. If material is not included in the article's Creative Commons licence and your intended use is not permitted by statutory regulation or exceeds the permitted use, you will need to obtain permission directly from the copyright holder. To view a copy of this licence, visit http://creativecommons.org/licenses/by$\mathrm{nc} / 4.0 /$.

\section{REFERENCES}

1. Desai MJ, Hargens LM, Breitenfeldt MD, Doth AH, Ryan MP, Gunnarsson C, et al. The rate of magnetic resonance imaging in patients with spinal cord stimulation. Spine. 2005;40(9):E531-7.

2. Jotwani R, Mehta N, Baig E, Gupta A, Gulati A. Neuromodulation and the epidemiology of magnetic resonance utilization for lung, breast, colon, and prostate cancer. Neuromodulation. 2020;23: 912.

3. Andres JD, Valía JC, Cerda-Elmedo G, Quiroz C, Villanueva V, Martinez-Sanjuan V, et al. Imaging in patients with spinal neurostimulation systems. Anesthesiology. 2007;106(4):779-86.
4. Sayed D, Chakravarthy K, Amirdelfan K, Kalia H, Meacham K, Shirvalkar P, Falowski S, Petersen E, Hagedorn JM, Pope J, Leever J, Deer T. A comprehensive practice guideline for magnetic resonance imaging compatibility in implanted neuromodulation devices. Neuromodulation. 2020;23:893-911.

5. Rubino S, Adepoju A, Kumar V, Prusik J, Murphy N, Owusu-Sarpong S, et al. MRI conditionality in patients with spinal cord stimulation devices. Stereotact Funct Neurosurg. 2016;94(4):254-8.

6. Abejon D, Feler CA. Is impedance a parameter to be taken into account in spinal cord stimulation? Pain Physician. 2007;10:533-40.

7. Lempka SF, Johnson MD, Miocinovic S, Vitek JL, McIntyre CC. Current-controlled deep brain stimulation reduces in vivo voltage fluctuations observed during voltage-controlled stimulation. Clin Neurophysiol. 2010;121(12):2128-33.

8. De Andres J, Valia JC, Cerda-Olmedo G, Quiroz C, Villanueva V, Martinez-Sanjuan V, et al. Magnetic resonance imaging in patients with spinal neurostimulation systems. Anesthesiology. 2007;106(4):779-86.

9. Zannou AL, Khadka N, FallahRad M, Truong DQ, Kopell $\mathrm{BH}$, Bikson M. Tissue temperature increases by a $10 \mathrm{kHz}$ spinal cord stimulation system: phantom and bioheat model. Neuromodulation. 2019. https://doi.org/10.1111/ner.12980.

10. Khadka N, Harmsen IE, Lozano AM, Bikson M. BioHeat Model of Kilohertz-Frequency Deep Brain Stimulation Increases Brain Tissue Temperature. Neuromodulation. 2020;23(4):489-95. https://doi. org/10.1111/ner.13120.

11. Zannou AL, Khadka N, Truong DQ, Zhang T, Esteller R, Hershey B, Bikson M. Temperature increases by kilohertz frequency spinal cord stimulation. Brain Stimul. 2019;12(1):62-72. https://doi. org/10.1016/j.brs.2018.10.007.

12. Schulz CF, Davis TT, Fung DA. Epidural lipomatosis as a cause for high impedance values during a spinal cord stimulator trial. PM\&R. 2013;5(8):729-31. https://doi.org/10.1016/j.pmrj.2013.04.021.

13. Miller JP, Eldabe S, Buchser E, Johanek LM, Guan Y, Linderoth B. Parameters of spinal cord stimulation and their role in electrical charge delivery: a review. Neuromodulation. 2016;19(4):373-84. https://doi. org/10.1111/ner.12438.

14. Shellock FG, Crues JV. MR procedures: biologic effects, safety, and patient care. Radiology. 2004;232:635-52. 
15. Shah R, Smith H, Chung J, Hegazi A, Racz G. Cervical spinal cord neoplasm in a patient with an implanted cervical spinal cord stimulator: the controversial role of magnetic resonance imaging: a case report. Pain Physician. 2004;7:273-8.

16. Roguin A, Zviman MM, Meininger GR, Rodrigues ER, Dickfeld TM, Bluemke DA, et al. Modern pacemaker and implantable cardioverter/defibrillator systems can be magnetic resonance imaging safe: in vitro and in vivo assessment of safety and function at 1.5 T. Circulation. 2004;110:475-82.

17. Kumar K, Hunter G, Demeria D. Spinal cord stimulation in treatment of chronic benign pain: challenges in treatment planning and present status, a 22-year experience. Neurosurgery. 2006;58:481-96.

18. Cameron T. Safety and efficacy of spinal cord stimulation for the treatment of chronic pain: a 20-year literature review. J Neurosurg. 2004;100: 254-67.

19. Deer TR, Mekhail N, Provenzano D, Pope J, Krames E, Thomson S, et al. The appropriate use of neurostimulation: avoidance and treatment of complications of neurostimulation therapies for the treatment of chronic pain. Neuromodul Technol Neural Interface. 2014;17(6):571-98.

20. North RB, Recinos VR, Attenello FJ, Shipley J, Long DM. Prevention of percutaneous spinal cord stimulation electrode migration: a 15-year experience. Neuromodul Technol Neural Interface. 2014;17(7): 670-7.

21. Mekhail NA, Mathews M, Nageeb F, Guirguis M, Mekhail MN, Cheng J. Retrospective review of 707 cases of spinal cord stimulation: indications and complications. Pain Pract. 2011;11(2):148-53.
22. Ranson M, Pope JE, Deer T, Pope JE. Complications of spinal cord stimulation. Reducing risks and complications of interventional pain procedures. Philadelphia: Elsevier Saunders; 2012. p. 3-10.

23. Alò K, Varga C, Krames E, Prager J, Holsheimer J, Manola L, et al. Factors affecting impedance of percutaneous leads in spinal cord stimulation. Neuromodul Technol Neural Interface. 2006;9: 128-35.

24. de Jongste MJ, Nagelkerke D, Hooyschuur CM, Journee HL, Meyler PW, Staal MJ, et al. Stimulation characteristics, complications, and efficacy of spinal cord stimulation systems in patients with refractory angina: a prospective feasibility study. Pacing Clin Electrophysiol. 1994;17(11):1751-60.

25. Cameron T, Alo KM. Effects of posture on stimulation parameters in spinal cord stimulation. Neuromodulation. 1998;1:177-83.

26. Olin JC, Kidd DH, North RB. Postural changes in spinal cord stimulation perceptual thresholds. Neuromodulation. 1998;1:171-5.

27. Ross E, Abejon D. Improving patient experience with spinal cord stimulation: implications of position-related changes in neurostimulation. Neuromodulation. 2014;17:36-41.

28. Russo RJ, Costa HS, Silva PD, Anderson JL, Arshad A, Biederman RW, et al. Assessing the risks associated with MRI in patients with a pacemaker or defibrillator. N Engl J Med. 2017;376(8):755-64.

29. Chen X, Steckner M. Electromagnetic computation and modeling in MRI. Med Phys. 2017;44(3): 1186-203. 